\title{
Calibration of Resistance Factor for Design of Pile Foundations
}

2

\section{Considering Feasibility Robustness}

3

4

Dian-Qing $\mathrm{Li}^{1}$, Xing Peng ${ }^{2}$, Sara Khoshnevisan ${ }^{3}$, C. Hsein Juang ${ }^{4 *}$

5

$6 \quad{ }^{1}$ State Key Laboratory of Water Resources and Hydropower Engineering Science, Wuhan

7 University, 8 Donghu South Road, Wuhan 430072, China. Email: dianqing@whu.edu.cn

$8{ }^{2}$ State Key Laboratory of Water Resources and Hydropower Engineering Science, Wuhan

9 University, 8 Donghu South Road, Wuhan 430072, China. Email: px09@whu.edu.cn

$10{ }^{3}$ Glenn Department of Civil Engineering, Clemson University, Clemson, SC 29634, USA.

11 Email: skhoshn@g.clemson.edu

$12{ }^{4}$ Key Laboratory of Road and Traffic Engineering of the Ministry of Education, Tongji

13 University, Shanghai 201804, China; Glenn Department of Civil Engineering, Clemson

14 University, Clemson, SC 29634, USA. Email: hsein@clemson.edu

$15 *$ Corresponding author: C. H. Juang (Email: hsein@ clemson.edu).

16 
17 Abstract: The resistance factor for pile foundations in load and resistance factor design (LRFD)

18 is traditionally calibrated considering target reliability index $\left(\beta_{T}\right)$ and statistics of load and

19 resistance bias factors. However, the resistance bias factor is hard to quantify statistically.

20 Consequently, the design obtained using the calibrated resistance factor can still miss $\beta_{T}$ if the

21 variation in resistance bias factor has been underestimated. In this paper, we propose a new

22 resistance factor calibration approach to address this dilemma by considering "feasibility

23 robustness" of design in the calibration process. Herein, the feasibility robustness is defined as

24 a probability that the $\beta_{T}$ requirement can still be satisfied even in the presence of uncertainty or

25 variation in the computed bearing capacity. For illustration, LRFD approach for pile

26 foundations commonly used in Shanghai, China is examined. Emphasis is placed on re-

27 calibration of resistance factors at various feasibility robustness levels, with due consideration

28 of the variation in the resistance bias factor. A case study is presented to illustrate the use of the

29 re-calibrated resistance factors. The results show that the feasibility robustness is gained at the

30 expense of cost efficiency; in other words, the two objectives are conflicting. To aid in the

31 design decision-making, an optimal feasibility robustness level and corresponding resistance

32 factors are suggested in the absence of a designer's preference.

34 Keywords: Pile foundations; Load and resistance factor design; Uncertainty; Target reliability 35 index; Feasibility robustness; Calibration. 


\section{Introduction}

Foundations have traditionally been designed based on the allowable stress design

(ASD) approach, which normally employs a single global factor of safety $(F S)$ to cope with all uncertainties associated with load and resistance (e.g., Bathurst et al. 2011; Reddy and Stuedlein 2013; Bach and van Gelder 2014; Huang et al. 2016). However, the nominal FS obtained from a deterministic method cannot accurately reflect the true level of safety (Fenton et al. 2015; Li et al. 2015). Currently, the load and resistance factor design (LRFD) approach, which is a simpler variant of the reliability-based design (RBD) method, has been gaining acceptance. Compared with ASD approach, the LRFD approach that is based on reliability theory can reasonably consider load and resistance uncertainties in the design (Reddy and Stuedlein 2013; Li et al. 2016). The LRFD approach generally uses load factors and resistance factor to account for the uncertainty in load and resistance, respectively. In recent years, extensive research (e.g., Yoon and O'Neill 1997; Paikowsky 2004; AASHTO 2007; Kwak et al. 2010; Yu et al. 2012; Li et al. 2015) was conducted to calibrate resistance factor for the design of pile foundation for a given set of load factors. Generally, the resistance factor is calibrated to a prescribed target reliability index $\beta_{T}$ considering the statistics of load and resistance bias factors (Zhang et al. 2006; Yoon et al. 2008).

In LRFD, the resistance bias factor is defined as the ratio of the measured bearing capacity from a load test to the predicted (or computed) bearing capacity by a static bearing capacity model, and is modeled as a random variable reflecting mainly the uncertainty in the model that is used to compute the capacity. A proper statistical characterization of resistance bias factor requires collection of reliable static load test data, which is the most important task for LRFD calibration (Kwak et al. 2010). In practice, however, the resistance bias factor statistics are hard to ascertain, particularly when the data are limited in quality and/or quantity 61 (Allen 2005). Thus, uncertainty is inherent in the derived statistical parameters of the resistance 
bias factor. Unfortunately, the resistance factor calibrated for LRFD is very sensitive to the uncertainty in the resistance bias factor. Consequently, a design obtained using the calibrated resistance factor may not achieve $\beta_{T}$ (i.e., the design is not feasible) if the variation in the resistance bias factor is underestimated.

To address this dilemma, the authors propose a new approach for resistance factor calibration that considers explicitly the feasibility robustness of design (Parkinson et al. 1993). Emphasis of this paper is placed on re-calibration of resistance factor with due consideration of variation in the resistance bias factor. By considering the feasibility robustness, design using the re-calibrated resistance factor will always satisfy the $\beta_{T}$ requirement to the extent defined by engineer even if uncertainty exists in the computed capacity.

It should be noted that the robustness design concept is not new; in fact, it was introduced by Taguchi (1986) and has been used widely in various engineering fields (e.g., Tsui 1992; Chen et al. 1996; Doltsinis et al. 2005; Park et al. 2006; Beyer and Sendhoff 2007; Lee et al. 2010; Khoshnevisan et al. 2016; Peng et al. 2016). Furthermore, examples of geotechnical design with LRFD approach considering design robustness have been reported (Juang et al. 2013; Gong et al. 2016a). However, this paper represents the first attempt at introducing the robustness concept into the LRFD calibration. The novelty of this paper is evidenced in the results presented.

This paper is outlined as follows. First, the traditional approach of resistance factor calibration and its possible drawback are presented through a LRFD calibration practice of pile foundations in Shanghai, China. Next, the feasibility robustness concept is introduced, followed by the development of the new resistance factor calibration approach considering feasibility robustness. Then, the resistance factors are re-calibrated at various predefined levels of feasibility robustness and illustrated through a bored pile design example. Finally, a most preferred feasibility robustness level and the corresponding resistance factors are suggested in 
the absence of a designer's preference.

88

\section{Traditional Approach for Resistance Factor Calibration}

In this section, the traditional resistance factor calibration process is reviewed using an example reported by Li et al. (2015) that describes Shanghai, China experience. In Li et al. (2015), resistance factors for total load-carrying capacity are calibrated for driven piles and bored piles designed by three commonly used methods in Shanghai, i.e., the static load testbased method (LT method), the design table method (DT method), and the cone penetration test-based method (CPT method). The details of these methods are summarized in Appendix I. Let $R, Q_{D}$, and $Q_{L}$ denote total capacity, dead load, and live load, respectively. The design equation in Shanghai can be expressed as:

$$
\frac{R_{n}}{\gamma_{R}}=\gamma_{D} Q_{D n}+\gamma_{L} Q_{L n}
$$

where $R_{n}, Q_{D n}$, and $Q_{L n}$ are the nominal values for $R, Q_{D}$, and $Q_{L}$, respectively; and $\gamma_{R}, \gamma_{D}$, and $\gamma_{L}$ are the partial factors for $R, Q_{D}$, and $Q_{L}$, respectively. Note that in some codes, such as AASHTO (2007), a partial factor $\phi$ is applied to resistance in a form such that $\gamma_{R}=1 / \phi$. for resistance and loads, reliability index $\beta$ can be calculated using first order second moment method as (after Withiam et al., 2001; Zhang et al. 2005):

105

$$
\beta \approx \frac{\ln \left(\frac{\lambda_{R} \gamma_{R}\left(\gamma_{D}+\gamma_{L} \rho\right)}{\lambda_{D}+\lambda_{L} \rho} \sqrt{\frac{1+\mathrm{COV}_{Q}^{2}}{1+\mathrm{COV}_{R}^{2}}}\right)}{\sqrt{\ln \left[\left(1+\mathrm{COV}_{R}^{2}\right)\left(1+\mathrm{COV}_{Q}^{2}\right)\right]}}
$$

106 where $\lambda_{R}, \lambda_{D}$, and $\lambda_{L}$ are mean bias factors of resistance, dead load, and live load, respectively; $107 \rho$ is the live load to dead load ratio; $Q$ is the total load (i.e., $Q=Q_{D}+Q_{L}$ ); $\operatorname{COV}_{R}$ and $\operatorname{COV}_{Q}$ 
According to Li et al. (2015), $\operatorname{COV}_{Q}$ can be calculated as:

$$
\operatorname{COV}_{Q}=\frac{1}{1+\rho} \sqrt{\mathrm{COV}_{D}^{2}+\rho^{2} \mathrm{COV}_{L}^{2}}
$$

where $\mathrm{COV}_{D}$ and $\mathrm{COV}_{L}$ are COVs of dead load bias factor and live load bias factor, respectively. As noted in Zhang et al. (2004), when an empirical relationship is used to compute the bearing capacity, the computed capacity is subjected to two types of uncertainties, i.e., the within-site variability and the cross-site variability. The within-site variability is mainly caused by the inherent variability of soil properties in the zone influencing each pile and by the construction errors associated with the site-specific workmanship. The cross-site variability is mainly caused by the regional variation in soil properties and by the construction errors associated with the workmanship in a region. In Li et al. (2015), both the within-site variability and the cross-site variability of the pile capacity are considered; thus $\lambda_{R}$ and $\operatorname{COV}_{R}$ can be further written as:

$$
\lambda_{R}=\lambda_{R 1} \lambda_{R 2}
$$

$$
\mathrm{COV}_{R}=\sqrt{\mathrm{COV}_{R 1}^{2}+\mathrm{COV}_{R 2}^{2}}
$$

where $\lambda_{R 1}$ and $\mathrm{COV}_{R 1}$ are the mean and $\mathrm{COV}$ of the bias factor accounting for within-site variability, respectively; and $\lambda_{R 2}$ and $\mathrm{COV}_{R 2}$ are the mean and $\mathrm{COV}$ of the bias factor accounting for cross-site variability, respectively.

In resistance factor calibration, a target reliability index $\beta_{T}$ is pre-defined. Based on Eq. (2), the value of $\gamma_{R}$ required to achieve $\beta_{T}$ can be obtained as:

$$
\gamma_{R}=\frac{\lambda_{D}+\lambda_{L} \rho}{\lambda_{R}\left(\gamma_{D}+\gamma_{L} \rho\right)} \sqrt{\frac{1+\mathrm{COV}_{R}^{2}}{1+\mathrm{COV}_{Q}^{2}}} \exp \left(\beta_{T} \sqrt{\ln \left[\left(1+\mathrm{COV}_{R}^{2}\right)\left(1+\mathrm{COV}_{Q}^{2}\right)\right]}\right)
$$

Eq. (6) shows that $\gamma_{R}$ is a function of $\beta_{T}$, load bias factor statistics, and resistance bias factor statistics. The load bias factor statistics employed by Li et al. (2015) are those used in the national code for foundation design in China (MOC, 2002): $\lambda_{D}=1.0, \lambda_{L}=1.0, \operatorname{COV}_{D}=$ 
132 0.07, and $\operatorname{COV}_{L}=0.29$. Based on MOC (2002), load partial factors $\gamma_{D}=1.0$ and $\gamma_{L}=1.0$ are

133 adopted; additionally, a live load to dead load ratio of $\rho=0.2$ is used (Li et al. 2015). The

134 resistance bias factor statistics (i.e., $\lambda_{R}$ and $\mathrm{COV}_{R}$ ) can be obtained by conducting statistical 135 analysis on cases with both static load test and prediction results.

136 The within-site variability can be characterized by comparing capacities of piles within 137 a site. In Li et al. (2015), a load test database consisting of 146 piles from 32 sites and another 138 database comprising 37 piles from 10 sites were used to characterize the within-site variability 139 for driven piles and bored piles, respectively. In these load tests, piles with identical geometry 140 at each site were loaded until failure occurred. The ultimate bearing capacity was determined 141 with a comprehensive analysis on the load-displacement $(Q-s)$ curve and the corresponding displacement-logarithm of time $(s-\lg t)$ curve. The load at the start point of a steep drop on the

$143 Q$-s curve and the load beyond which the settlement will not converge on the $s$-lgt curve was 144 taken as the ultimate bearing capacity (SUCCC 2010; Zhang et al. 2005). Details on these piles are summarized in Table 1 and Table 2.

According to Zhang et al. (2004), the within-site variability refers to the variability in

147 the pile capacity values within a site and thus, the mean of these values is truly reflected by the 148 mean of the measured capacity values, which is based on the proven theory that the sample 149 mean is an unbiased estimate of the population mean. Therefore, the within-site variability of 150 the pile capacity prediction is unbiased (Zhang et al. 2004; Li et al. 2015), i.e., $\lambda_{R 1}=1$. On the 151 other hand, the value of $\operatorname{COV}_{R 1}$ is determined by calculating the $\mathrm{COV}$ of the measured 152 capacities of the piles within a site. Note that values of $\operatorname{COV}_{R 1}$ vary from site to site. The values 153 of $\mathrm{COV}_{R 1}$ of driven piles are in the range of $0.031-0.155$ with a mean of 0.087 and a COV of 1540.36 . The values of $\mathrm{COV}_{R 1}$ of bored piles are in the range of $0.049-0.179$ with a mean of 0.093 and a COV of 0.44. In Li et al. (2015), as in other traditional LRFD calibration studies (e.g., Paikowsky 2004), the means of those $\operatorname{COV}_{R 1}$ values for driven piles and bored piles are adopted 
in calibration, as listed in Table 3, and the uncertainties in those $\mathrm{COV}_{R 1}$ values are ignored. The cross-site variability can be characterized by comparing the measured and

159 predicted bearing capacities of piles from different sites. A bearing capacity ratio is first

160 obtained for each site by dividing the mean of measured bearing capacities at this site by the

161 computed bearing capacity (e.g., predicted capacity using DT method for bored piles listed in

162 Table 2). The mean and the COV of the bearing capacity ratios are regarded as the estimates of $\lambda_{R 2}$ and $\mathrm{COV}_{R 2}$. For the piles designed using LT method, the computed capacity is taken as the mean of measured capacities, thus the values of bearing capacity ratio for all sites are taken as 1 which lead to $\lambda_{R 2}=1$ and $\operatorname{COV}_{R 2}=0$. For the bored piles designed using DT method, the

166 bearing capacity ratios for 10 sites in Table 2 are calculated (e.g., a ratio of 0.808 for site 1 ).

167 The mean and COV of the 10 ratios are computed and taken as $\lambda_{R 2}$ and $\mathrm{COV}_{R 2}$, respectively, i.e., $\lambda_{R 2}=0.996$ and $\mathrm{COV}_{R 2}=0.184$, for the DT method for bored piles. Note that the driven piles in Table 1 are not used for characterizing the cross-site variability using DT method and CPT method. In Li et al. (2015), for driven piles designed using DT method and CPT method, the values of $\lambda_{R 2}$ and $\mathrm{COV}_{R 2}$ based on the previous design code are reviewed and adopted. The characterization of cross-site variability for different design methods and different piles are also summarized in Table 3.

The statistics of resistance bias factor (i.e., $\lambda_{R}$ and $\mathrm{COV}_{R}$ ) are then obtained using Eqs. (4) and (5) based on the characterized within-site variability and cross-site variability. Among 176 the design methods, the LT method has the smallest COV, as it is free from cross-site variability.

177 On the other hand, the DT method has the largest uncertainty. Having obtained the statistics of 178 load bias factor and resistance bias factor, the required $\gamma_{R}$ corresponding to a specified target 179 reliability index, say, $\beta_{T}=3.7$ (Li et al. 2015), can be calculated using Eq. (6). The calibrated 180 values of $\gamma_{R}$ for different design methods and different piles obtained by Li et al. (2015) are 181 listed in Table 3. 
$183=0.093$, the mean values of the respective COVs, are adopted for the analysis of driven piles 184 and bored piles, respectively. However, $\operatorname{COV}_{R 1}$ actually varies from site to site as seen in Tables 1851 and 2. This variation in $\mathrm{COV}_{R 1}$ is not reflected in the traditional resistance factor calibration; 186 and as such, uncertainty in the computed capacity is not fully accounted for when the calibrated $187 \gamma_{R}$ is applied to a future case. To characterize the distribution of $\operatorname{COV}_{R 1}$, Fig. 1 (a) and (b) illustrates the cumulative frequency of observed $\mathrm{COV}_{R 1}$ from the adopted database (see Tables 1 and 2) for driven piles and bored piles, respectively. Lognormal cumulative distribution

190 function (CDF) curve is also plotted in Fig. 1 to fit the data set. Approximations are 191 superimposed on the CDF curve using the computed values of the mean and COV. Visually, 192 the lognormal CDF matches the cumulative frequency of $\operatorname{COV}_{R 1}$ well. Therefore, $\operatorname{COV}_{R 1}$ is treated as a lognormal random variable in this paper. resistance factors in Li et al. (2015), Monte Carlo Simulation (MCS) (Jiang et al. 2015) is performed to generate 5000 random samples of $\mathrm{COV}_{R 1}$ and the corresponding values of $\beta$ are computed using Eq. (2) for different types of piles and different design methods. Fig. 2 shows histograms of relative frequency of $\beta$ for different types of piles and different design methods. It is observed that $\beta$ values distribute in wide ranges and many of the designs cannot achieve $\beta_{T}=3.7$ (i.e., $\beta<\beta_{T}$ ). Furthermore, Fig. 2 also shows the cumulative frequency curves of $\beta$. With the aid of these cumulative curves, the probability of $\left(\beta<\beta_{T}\right)$ can be readily obtained. The values of this probability for driven piles designed with the LT method, DT method, and CPT method are 0.466, 0.511, and 0.485, respectively. For bored piles using LT method and DT method, the values are 0.442 and 0.500 , respectively. The implication is that when $\gamma_{R}$ obtained from the traditional LRFD calibration that does not consider the variation in $\operatorname{COV}_{R 1}$ is used, there is a high chance that the safety requirement (i.e., $\beta \geq \beta_{T}$ ) will not be satisfied (i.e., the 
design is not feasible). In other words, the design using this $\gamma_{R}$ may not meet the safety requirement due to the uncertainty in the computed capacity. This is a drawback of the traditional resistance factor calibration. To reduce the chance for the violation of safety requirement, or to improve the feasibility robustness of the design using partial factors, a new resistance factor calibration approach considering robustness is proposed.

\section{Resistance Factor Calibration Considering Robustness}

\subsection{Feasibility robustness}

In this paper, "feasibility robustness" (Parkinson et al. 1993) is adopted to measure the robustness of partial-factor design with respect to uncertain parameters (i.e., $\mathrm{COV}_{R 1}$ ) in the calibration process. Herein, the feasibility robustness is the robustness against the uncertainty in the assessed safety level, and is defined as the probability that $\beta_{T}$ can still be satisfied even with the variation in $\mathrm{COV}_{R 1}$. Symbolically, feasibility robustness is formulated as (Juang and

Wang 2013; Juang et al. 2013):

$$
P\left[\left(\beta-\beta_{T}\right) \geq 0\right] \geq P_{0}
$$

where $P\left[\left(\beta-\beta_{T}\right) \geq 0\right]$ is the probability that $\beta_{T}$ is satisfied; and $P_{0}$ is a pre-defined acceptable level of this probability (i.e., feasibility robustness). of the corresponding $\beta$. As shown in Fig. 2, the values of $P\left[\left(\beta^{-} \beta_{T}\right) \geq 0\right]$ of those piles designed with the calibrated $\gamma_{R}$ can be evaluated based on the corresponding cumulative frequency curves obtained from MCS. The results are summarized in Table 4. For example, for driven piles designed using LT method with $\gamma_{R}=1.53$, the value of $P[(\beta-3.7) \geq 0]$ is 0.534 . If the feasibility robustness level is pre-selected as $P_{0}=0.6$, the design using $\gamma_{R}=1.53$ cannot meet the feasibility robustness requirement (since 0.534 is less than the prescribed level of 0.6). Although MCS provides a rigorous way to determine the feasibility robustness $P\left[\left(\beta-\beta_{T}\right) \geq 0\right]$, 
232 it is time consuming. Simulations show that the resulting histogram of $\beta$ can be approximated

233 well with a normal distribution, as depicted in Fig. 2. Thus, if the mean and standard deviation

234 of $\beta$, denoted as $\mu_{\beta}$ and $\sigma_{\beta}$, can be determined, the feasibility robustness of design can readily

235 be computed with the assumption of normal distribution as (Juang et al., 2013; Wang et al.

236 2013):

237

$$
P\left[\left(\beta-\beta_{T}\right) \geq 0\right]=\Phi\left(\frac{\mu_{\beta}-\beta_{T}}{\sigma_{\beta}}\right) \geq P_{0}
$$

238

240

241

242

243

244

246

where $\Phi$ is cumulative standard normal distribution function.

Therefore, the evaluation of feasibility robustness is reduced to a task of determining $\mu_{\beta}$ and $\sigma_{\beta}$. In this paper, seven point estimate method (PEM) developed by Zhao and Ono (2000) is adopted to estimate $\mu_{\beta}$ and $\sigma_{\beta}$. Since $\beta$ is the function of single random variable $\operatorname{COV}_{R 1}$ in this problem, the seven-point PEM first assigns the values of $\mathrm{COV}_{R 1}$ at each estimating point; then $\beta_{i}(i=1,2, \ldots, 7)$ is evaluated at each point using Eq. (2). The resulting seven $\beta_{i}$ values are then used to compute the $\mu_{\beta}$ and $\sigma_{\beta}$, as (Zhao and Ono 2000):

$$
\begin{aligned}
& \mu_{\beta}=\sum_{i=1}^{7} P_{i} \beta_{i} \\
& \sigma_{\beta}{ }^{2}=\sum_{i=1}^{7} P_{i}\left(\beta_{i}-\mu_{\beta}\right)^{2}
\end{aligned}
$$

where $P_{i}(i=1,2, \ldots, 7)$ are the weights corresponding to estimating points as per Zhao and Ono (2000). The readers are referred to Zhao and Ono (2000) for details on PEM.

Using PEM, the feasibility robustness of the design using the calibrated $\gamma_{R}$ reported by Li et al. (2015) are calculated and displayed in Table 4. Comparing with the results computed with MCS, it shows that the two approaches are quite consistent and the PEM-based approach for feasibility robustness (Eqs. 8-10) is judged adequate in terms of accuracy.

\subsection{Calibration of resistance factor with robustness consideration}

The aforementioned procedure to evaluate feasibility robustness of a design using the 
existing $\gamma_{R}$ actually is the inverse of the task of resistance factor calibration considering robustness. Here, the resistance factor calibration considering robustness is a process of determining the value of $\gamma_{R}$ such that the resulting design can achieve the pre-defined feasibility robustness level, i.e., $P[(\beta-\beta T) \geq 0]=P_{0}$.

The resistance factor calibration process considering feasibility robustness proposed herein can be implemented using a trial-and-error approach, in which a trial $\gamma_{R}$ is assumed and then checked against feasibility robustness requirement using MCS or PEM, followed by revision of the $\gamma_{R}$, if necessary. Alternatively, it is noted that the feasibility robustness can be expressed as a function of $\gamma_{R}$, e.g., in a form of $P\left[\left(\beta-\beta_{T}\right)\right]=\mathrm{G}\left(\gamma_{R}\right)$, by combining Eqs. (2), (8), (9), and (10). Thus, once the target $P_{0}$ is defined, the corresponding $\gamma_{R}$ can be readily determined by solving the equation $\mathrm{G}\left(\gamma_{R}\right)=P_{0}$, in lieu of the trial-and-error process.

In the present study, six feasibility robustness levels (i.e., $P_{0}=0.5,0.6, \ldots, 0.9,0.99$ ), are selected for illustration purpose. Among these pre-defined target levels, the lower bound $P_{0}$ $=0.5$ is selected to ensure an average level that $\mu_{\beta} \geq \beta_{T}$ as per Eq. (8); the upper bound $P_{0}=$ 0.99 represents an extreme design scenario. To be consistent with Li et al. (2015), $\beta_{T}=3.7$ is adopted in the calibration. Using the proposed calibration procedure (i.e., solving $\mathrm{G}\left(\gamma_{R}\right)=P_{0}$ ), the values of $\gamma_{R}$ compatible with $\gamma_{L}=1.0$ and $\gamma_{D}=1.0$ to achieve pre-defined target robustness levels for different types of piles and different design methods are determined and the results are given in Table 5. For example, when the feasibility robustness level is set as $P_{0}=0.5$, the values of $\gamma_{R}$ for driven piles designed with LT method, DT method, and CPT method are 1.52, 1.95, and 1.72, respectively; for bored piles designed using LT method and DT method, the values are 1.53 and 2.30, respectively. Noted that the somewhat unusual load factors of 1.0

277 adopted from Chinese and Shanghai codes should only be used in conjunction with the resistance factors calibrated to the target reliability index under this setting of load factors. As 
$F S$ (see Eq. (1)). Note that the required $\gamma_{R}$ increases with increasing $P_{0}$, as expected. To achieve the same $P_{0}$, DT method requires larger $\gamma_{R}$, as it is associated with greater uncertainties while the required $\gamma_{R}$ for LT method is smaller due to the lower uncertainties involved with LT method. Thus, although a smaller nominal $F S$ is required in LT method, the reliability level and robustness level are indeed same as those using DT method that yield a larger nominal FS. This further illustrates the limitation of the ASD approach, i.e., the nominal $F S$ cannot accurately reflect the true level of safety. Using Table 5, the designer can first select the $P_{0}$ for a given project and then use the corresponding $\gamma_{R}$ to perform the design of piles. Such design is guaranteed to have a level of feasibility robustness of $P_{0}$ (meaning that the chance for the design to remain feasible regardless of the variation of $\mathrm{COV}_{R 1}$ is $\left.P_{0}\right)$.

Furthermore, the values of $\mu_{\beta}$ and $\sigma_{\beta}$ at various feasibility robustness levels corresponding to the resistance factors listed in Table 5 are calculated using Eqs. (9) and (10), and the results are summarized in Table 6 . Note that for the same $P_{0}$, piles designed with LT method have the largest $\mu \beta$, e.g., 4.38 for driven piles and 4.54 for bored piles when $P_{0}$ is 0.8 . This is consistent with the view that LT method is the most reliable. On the other hand, piles designed with DT method have the smallest $\mu_{\beta}$, e.g., 3.98 for both driven piles and bored piles when $P_{0}$ is 0.8 . It should also be noted that both the values of $\mu_{\beta}$ and $\sigma_{\beta}$ increase with increasing $P_{0}$. The implication is that feasibility robustness is primarily affected by $\mu_{\beta}$ as per Eq. (8).

\section{Design Example Using the Re-calibrated Resistance Factors}

To illustrate use of the calibrated resistance factors considering feasibility robustness listed in Table 5, a bored pile is designed using DT method for a sand profile. The bored pile with diameter $D=0.85 \mathrm{~m}$ shown in Fig. 3 is embedded at a depth of $L$, (i.e., the pile length is $L)$. The soil layer surrounding bored pile is divided into 5 sub-layers, as shown in Fig. 3. The 
given in Fig. 3. The bored pile in this problem is intended to carry axial compressive loads of $2500 \mathrm{kN}$ dead load $\left(Q_{D n}\right)$ and $500 \mathrm{kN}$ live load $\left(Q_{L n}\right)$. Using live load and dead load factors of 1.0 and 1.0 , respectively, the design load is $3000 \mathrm{kN}$.

Using the corresponding $\gamma_{R}$ in Table 5, the values of required pile length $L$ at various feasibility robustness levels can be determined by Eqs. (1) and (A1) using DT method, and the

310 design results are illustrated in Fig. 4. For example, the required depths for $P_{0}=0.5$ and $P_{0}=$ 3110.99 are $L=45.9 \mathrm{~m}$ and $L=53.6 \mathrm{~m}$, respectively. It can be seen that the value of $L$ increases with increasing $P_{0}$. That is to say, larger pile length is required to achieve higher feasibility robustness levels (i.e. larger $P_{0}$ values). Note that the $L$ (at a given $D$ ) can be treated as an index of construction cost. The implication is that design with high robustness against variation in the computed capacity can always be achieved at the expense of cost efficiency. However, this may not be desired and a tradeoff between cost efficiency and design robustness must be made. The discussion in the section that follows focuses on this tradeoff issue.

\section{Further Discussion}

Table 5 provides the resistance factors calibrated to $\beta_{T}=3.7$ and various target levels of feasibility robustness $P_{0}$. Designers can select $\gamma_{R}$ corresponding to the desired $P_{0}$ for a given project. Generally, a design with higher feasibility robustness and relatively lower cost is desired. However, as shown in the above bored pile design example, feasibility robustness and cost efficiency are conflicting to each other. When there is no strong preference by the designer, a tradeoff decision may be based on an optimization of $\gamma_{R}$ performed with respect to two objectives, design robustness and cost efficiency.

Note that according to Eq. (1), for a given loading, use of a higher $\gamma_{R}$ implies the need for a higher nominal bearing capacity, which in turn, points to the need for a larger $L$ and thus, a greater cost. Thus, the cost can be effectively reflected in $\gamma_{R}$. In this study, a discrete design 
space is considered for the optimization of $\gamma_{R}$, in which $P_{0}$ will be selected from the range of 0.5 to 0.99 with an increment of 0.01 . The multi-objective optimization is set up as follows:

Find: $\quad$ An optimal $\gamma_{R}$ compatible with $\gamma_{L}=1.0$ and $\gamma_{D}=1.0$

Subject to: $\mathrm{G}\left(\gamma_{R}\right)=P_{0} \in\{0.5,0.51,0.52, \ldots, 0.99\}$

Objectives: Maximizing the feasibility robustness (in terms of $P_{0}$ ) Minimizing the construction cost (in terms of $\gamma_{R}$ )

The values of $\gamma_{R}$ corresponding to the 50 potential feasibility robustness levels are determined by solving $\mathrm{G}\left(\gamma_{R}\right)=P_{0}$, respectively. Fig. 5 shows the variation of calibrated $\gamma_{R}$ as a function of $P_{0}$, for different combinations of pile types and design methods. As shown in Fig.

5, $\gamma_{R}$ increases as $P_{0}$ increases, and the curves have the similar trend with the relationship between $L$ and $P_{0}$ shown in Fig. 4, as expected. Thus, a tradeoff exists between design robustness and cost efficiency; the tradeoff relationship is presented here as a Pareto front (Cheng and Li 1997; Khoshnevisan et al. 2014; Gong et al. 2016b). The knee point (Deb and Gupta 2011) on the Pareto front conceptually yields the best compromise among conflicting objectives. In other words, the knee point may be taken as the most preferred choice. In this study, the minimum distance approach (Khoshnevisan et al. 2014; Gong et al. 2016a) is used to determine the knee point, in which a point that has the minimum distance from the "utopia point" in a normalized space of the objective functions is taken as the knee point. Interested readers are referred to Khoshnevisan et al. (2014) and Gong et al. (2016a) for additional details on the minimum distance approach.

With the minimum distance approach, knee points for different types of piles designed using different methods are readily identified, as also shown in Fig. 5. Consider, for example, driven piles designed using LT method, the knee point identified in Fig. 5(a) has the following 
parameters $P_{0}=0.86$ and $\gamma_{R}=1.68$. As can be observed in Fig. 5(a), on the left side of knee point, the curve is relatively flat, indicating a slight reduction in $\gamma_{R}$ (i.e., cost) would lead to a large decrease in design robustness (as reflected by a markedly decrease in $P_{0}$ ), which is undesirable. On the other side of the knee point, the slope is relatively sharp, indicating a slight gain in $P_{0}$ (i.e., a slight improvement of feasibility robustness) requires a large increase in $\gamma_{R}$, rendering it cost inefficient. Therefore, the knee point on the Pareto front represents the best compromise between design robustness and cost efficiency.

The values of $P_{0}$ and $\gamma_{R}$ corresponding to those knee points shown in Fig. 5 are summarized in Table 7 . Note that the values of $P_{0}$ vary from 0.84 to 0.88 . For consistency and simplicity, in all scenarios, $P_{0}$ is set at 0.85 and the $\gamma_{R}$ values are adjusted slightly, and the final results are listed in Table 7, which are recommended for typical geotechnical practice. The previous bored pile example is redesigned herein using $\gamma_{R}=2.47$ selected form Table 7 compatible with $\gamma_{L}=1.0$ and $\gamma_{D}=1.0$. To meet $P_{0}=0.85$, the final $L$ is determined to be 48.75 $\mathrm{m}$ and is shown in Fig. 4.

\section{Concluding Remarks}

This paper presents a new resistance factor $\left(\gamma_{R}\right)$ calibration approach considering feasibility robustness. The new approach is demonstrated with a pile design calibration example that describes Shanghai, China experience. Herein, the feasibility robustness is defined as a probability that the safety requirement can still be satisfied even if the capacity of the designed system is uncertain (i.e., exhibiting significant variation) due to the uncertainty in resistance bias factors. With due consideration of the variation in the resistance bias factor, the proposed calibration approach aims to obtain $\gamma_{R}$ so that the resulting design is robust against uncertainty in the computed bearing capacity. 
calibrated $\gamma_{R}$ obtained from the traditional LRFD calibration process can still miss the target reliability index $\left(\beta_{T}\right)$ because of the underestimation of the variation in resistance bias factor. By considering feasibility robustness in the calibration process, $\gamma_{R}$ is re-calibrated in this study, which can be selected for future applications based on the desired feasibility robustness level. A case study is performed using the re-calibrated $\gamma_{R}$. It shows that feasibility robustness and cost efficiency are two conflicting objectives. To aid in decision-making in the design process, a feasibility robustness level of 0.85 and corresponding values of $\gamma_{R}$, which are obtained through a multi-objective optimization, are suggested in the absence of a designer's preference.

It should be noted that the calibrated resistance factors are obtained specifically for design of piles in Shanghai, as assumptions based on local practice are made. Further studies are warranted to confirm the general applicability of the proposed calibration approach.

\section{Acknowledgments}

The study on which this paper is based was supported in part by National Science

394 Foundation through Grant CMMI-1200117 (“Transforming Robust Design Concept into a

395 Novel Geotechnical Design Tool"). The results and opinions expressed in this paper do not 396 necessarily reflect the views and policies of the National Science Foundation. This work was 397 also supported by the National Science Fund for Distinguished Young Scholars (Project No. 398 51225903), and the National Natural Science Foundation of China (Project Nos. 51329901, 399 51579190, 51528901). The second author wishes to thank the Glenn Department of Civil 400 Engineering of Clemson University, South Carolina for hosting his two-year visit as an 401 exchange PhD student. The fourth author wishes to acknowledge the support of the Shanghai 402 Peak Discipline Research Group Construction Program through Key Laboratory of Road and 
403 Traffic Engineering of the Ministry of Education at Tongji University, Shanghai, China. 404 


\section{References}

406

407

408

409

410

411

412

413

414

415

416

417

418

419

420

421

422

423

424

425

426

427

428

429

AASHTO. (2007). LRFD Bridge Design Specifications, 4th ed. AASHTO, Washington, DC.

Allen, T. M. (2005). Development of Geotechnical Resistance Factors and Downdrag Load Factors for LRFD Foundation Strength Limit State Design: Reference Manual. US Department of Transportation, Federal Highway Administration, National Highway Institute.

Bach, D., and van Gelder, P. (2014). Incorporating set-up into LRFD method for drilled shafts. Georisk, 8(2), 81-91.

Beyer, H. G., and Sendhoff, B. (2007). Robust optimization-a comprehensive survey. Computer Methods in Applied Mechanics and Engineering, 196(33), 3190-3218.

Bathurst, R. J., Huang, B. Q., and Allen, T. M. (2011). Load and resistance factor design (LRFD) calibration for steel grid reinforced soil walls. Georisk, 5(3-4), 218-228.

Chen, W., Allen, J. K., Tsui, K. L., and Mistree, F. (1996). A procedure for robust design: minimizing variations caused by noise factors and control factors. Journal of Mechanical Design, 118(4), 478-485.

Cheng, F. Y., and Li, D. (1997). Multiobjective optimization design with Pareto genetic algorithm. Journal of Structural Engineering, 123(9), 1252-1261.

Deb, K., and Gupta, S. (2011). Understanding knee points in bicriteria problems and their implications as preferred solution principles. Engineering Optimization, 43(11), 11751204.

Doltsinis, I., Kang, Z., and Cheng, G. (2005). Robust design of non-linear structures using optimization methods. Computer Methods in Applied Mechanics and Engineering, 194(12), 1779-1795.

Fenton, G. A., Naghibi, F., Dundas, D., Bathurst, R. J., and Griffiths, D. V. (2015). Reliabilitybased geotechnical design in 2014 Canadian Highway Bridge Design Code. Canadian 
431

432

433

434

435

436

437

438

439

440

441

442

443

444

445

446

447

448

449

450

451

452

453

454

Gong, W., Juang, C. H., Khoshnevisan, S., and Phoon, K. K. (2016a). R-LRFD: Load and resistance factor design considering robustness. Computers and Geotechnics, 74, 74-87.

Gong, W., Tien, Y. M., Juang, C. H., Martin, J. R., and Zhang, J. (2016b). Calibration of empirical models considering model fidelity and model robustness-Focusing on predictions of liquefaction-induced settlements. Engineering Geology, 203, 168-177.

Huang, J. S., Kelly, R., Li, D. Q., Zhou, C. B., and Scott, S. (2016). Updating reliability of single piles and pile groups by load tests. Computers and Geotechnics, 73, 221-230.

Jiang, S. H., Li, D. Q., Cao, Z. J., Zhou, C. B., and Phoon, K. K. (2015). Efficient system reliability analysis of slope stability in spatially variable soils using Monte Carlo simulation. Journal of Geotechnical and Geoenvironmental Engineering, 141(2), 04014096.

Juang, C. H., and Wang, L. (2013). Reliability-based robust geotechnical design of spread foundations using multi-objective genetic algorithm. Computers and Geotechnics, 48 , 96-106.

Juang, C. H., Wang, L., Liu, Z. F., Ravichandran, N., Huang, H. W., and Zhang, J. (2013). Robust geotechnical design of drilled shafts in sand: New design perspective. Journal of Geotechnical and Geoenvironmental Engineering, 139(12), 2007-2019.

Khoshnevisan, S., Gong, W., Wang, L., and Juang, C. H. (2014). Robust design in geotechnical engineering-an update. Georisk, 8(4), 217-234.

Khoshnevisan, S., Wang, L., and Juang, C. H. (2016). Simplified procedure for reliability-based robust geotechnical design of drilled shafts in clay using spreadsheet. Georisk, 10(2), 121-134.

Kwak, K., Kim, K. J., Huh, J., Lee, J. H., and Park, J. H. (2010). Reliability-based calibration of resistance factors for static bearing capacity of driven steel pipe piles. Canadian 
Lee, J. H., Kim, T., and Lee, H. (2010). A study on robust indentation techniques to evaluate elastic-plastic properties of metals. International Journal of Solids and Structures, 47(5), 647-664.

Li, D. Q., Shao, K. B., Cao, Z. J., Tang, X. S., and Phoon, K.K. (2016). A generalized surrogate response aided-subset simulation approach for efficient geotechnical reliability-based design. Computers and Geotechnics, 74, 88-101

Li, J. P., Zhang, J., Liu, S. N., and Juang, C. H. (2015). Reliability-based code revision for design of pile foundations: Practice in Shanghai, China. Soils and Foundations, 55(3), 637-649.

MOC, 2002. Code for Design of Foundations (GB 50007-2002). Ministry of Construction (MOC) of China, Beijing. (In Chinese).

Park, G. J., Lee, T. H., Lee, K. H., and Hwang, K. H. (2006). Robust design: an overview. AIAA journal, 44(1), 181-191.

Parkinson, A., Sorensen, C., and Pourhassan, N. (1993). A general approach for robust optimal design. Journal of Mechanical Design, 115(1), 74-80.

Paikowsky, S. G. (2004). Load and resistance factor design (LRFD) for deep foundations. NCHRP Report 507, Transportation Research Board, Washington, D.C.

Peng, X., Li, D. Q., Cao, Z. J., Gong, W., and Juang, C. H (2016). Reliability-based robust geotechnical design using Monte Carlo simulation. Bulletin of Engineering Geology and the Environment, doi: 10.1007/s10064-016-0905-3.

Reddy, S.C., Stuedlein, A.W. (2013). Accuracy and reliability-based region-specific recalibration of dynamic pile formulas. Georisk, 7(3), 163-183. and Communications Commission (SUCCC), Shanghai (in Chinese). 
Taguchi, G. (1986). Introduction to quality engineering: Designing quality into products and processes, Quality Resources, White Plains, NY.

Tsui, K. L. (1992). An overview of Taguchi method and newly developed statistical methods for robust design. Iie Transactions, 24(5), 44-57.

Wang, L., Hwang, J. H., Juang, C. H., and Atamturktur, S. (2013). Reliability-based design of 485 rock slopes - A new perspective on design robustness. Engineering Geology, 154, 5663.

Withiam, J. L., Voytko, E. P., Barker, R. M., Duncan, J. M., Kelly, B. C., Musser, S. C., and Elias, V. (2001). Load and Resistance Factor Design (LRFD) for Highway Bridge Substructures, Publication No FHWA HI-98-032, NHI Course No. 13068. Federal Highway Administration, Washington D.C., USA.

Yoon, G., and O'Neill, M. (1997). Resistance factors for single driven piles from experiments. Journal of the Transportation Research Board, (1569), 47-54.

Yoon, S., Abu-Farsakh, M., Tsai, C., and Zhang, Z. (2008). Calibration of resistance factors for axially loaded concrete piles driven into soft soils. Transportation Research Record: Journal of the Transportation Research Board, (2045), 39-50.

497

Yu, X., Abu-Farsakh, M. Y., Yoon, S., Tsai, C., and Zhang, Z. (2012). Implementation of LRFD 497 of drilled shafts in Louisiana. Journal of Infrastructure Systems, 18(2), 103-112.

Zhang, L. M., Li, D. Q., and Tang, W. H. (2005). Reliability of bored pile foundations considering bias in failure criteria. Canadian Geotechnical Journal, 42(4), 1086-1093.

Zhang, L. M., Li, D. Q., and Tang, W. H. (2006). Level of construction control and safety of driven piles. Soils and foundations, 46(4), 415-425.

Zhang, L., Tang, W. H., Zhang, L., and Zheng, J. (2004). Reducing uncertainty of prediction from empirical correlations. Journal of Geotechnical and Geoenvironmental Engineering, 130(5), 526-534. 
505 Zhao, Y. G., and Ono, T. (2000). New point estimates for probability moments. Journal of 506 Engineering Mechanics, 126(4), 433-436.

507 


\section{Load Test-Based (LT) Method}

LT method is considered as the most reliable approach for pile design. When the static

511 load test is used to determine the design capacity, at least 3 piles or $1 \%$ of the total number of

512 production piles should be tested. However, if the number of production piles is smaller than

51350 , the number of piles to be tested can be reduced to a minimum of 2 . The ultimate pile

514 capacity at the site is chosen as the mean of the measured bearing capacities. For each pile, the

515 ultimate bearing capacity was determined by examining the load-displacement $(Q-s)$ curve and

516 the corresponding displacement-logarithm of time $(s-\lg t)$ curve. The load at the start point of a

517 steep drop on the $Q-s$ curve and the load beyond which the settlement will not converge on the

$518 s$-lgt curve was taken as the ultimate bearing capacity (SUCCC 2010; Zhang et al. 2005).

In LT method, the piles are initially designed based on the design table (DT) method or the cone penetration test-based (CPT) method. If static load tests show that the bearing capacity of the initially designed piles is not adequate and the design needs to be revised, the bearing capacity of the revised piles should also be measured by static load tests. LT method is often used for important projects, or when the site condition is complex, new construction methods are employed, or new types of piles are used.

\section{Design Table (DT) Method}

In DT method, the nominal bearing capacity of a pile is determined empirically based on the soil profile as:

$$
R_{n}=R_{t}+R_{s}=q_{t} A_{t}+U_{p} \sum_{i=1}^{n} f_{s i} z_{i}
$$


529 where $R_{t}$ is side resistance; $R_{s}$ is toe resistance; $q_{t}$ is unit toe resistance; $A_{t}$ is cross-section area

530 of pile end; $U_{p}$ is perimeter of pile; $f_{s i}$ is unit side resistance of the $i^{\text {th }}$ soil layer, $z i=$ thickness

531 of pile interfacing with the $i^{\text {th }}$ soil layer; and $n$ is the number of soil layers surrounding the pile.

532 Cone Penetration Test-based (CPT) Method

533 In CPT method, the bearing capacity of a pile is calculated using the following equation:

534

$$
R_{c}=R_{t}+R_{s}=\alpha_{b} q_{c t} A_{t}+U_{p} \sum_{i=1}^{n} f_{s i} z_{i}
$$

535 where $\alpha_{b}$ is correction factor; and $q_{c t}$ is cone tip resistance measured at the pile toe.

536 


\section{List of Tables}

Table 1. Summary of driven piles for code calibration (modified after Li et al. 2015)

Table 2. Summary of bored piles for code calibration (modified after Li et al. 2015)

Table 3. Summary of resistance bias factor statistics used in calibration and resulting calibrated partial factors (modified after Li et al. 2015)

Table 4. Feasibility robustness of calibrated partial factors in Li et al. (2015) obtained from MCS and PEM

Table 5. Calibrated partial factors $\left(\gamma_{R}\right)$ for total capacity at different feasibility robustness levels

Table 6. Values of $\mu_{\beta}$ and $\sigma_{\beta}$ at various feasibility robustness levels

Table 7. Calibrated partial factors obtained from knee point of Pareto front 
Table 1. Summary of driven piles for code calibration (modified after Li et al. 2015)

\begin{tabular}{|c|c|c|c|c|c|c|}
\hline \multirow{2}{*}{$\begin{array}{l}\text { Site } \\
\text { No. }\end{array}$} & \multirow[t]{2}{*}{ Site Name } & \multirow{2}{*}{$\begin{array}{l}\text { Dimension } \\
(\mathrm{mm})\end{array}$} & \multirow{2}{*}{$\begin{array}{l}\text { No. of } \\
\text { piles }\end{array}$} & \multirow{2}{*}{$\begin{array}{l}\text { Measured ultimate } \\
\text { bearing capacity }(\mathrm{kN})\end{array}$} & \multicolumn{2}{|c|}{$\begin{array}{l}\text { Statistics of measurec } \\
\text { bearing capacity }\end{array}$} \\
\hline & & & & & Mean $(\mathrm{kN})$ & $\mathrm{COV}$ \\
\hline 1 & Shanghai Jiangping High School & $250 \times 250$ & 6 & $\begin{array}{l}558 ; 496 ; 558 ; 558 ; \\
558 ; 550\end{array}$ & 546 & 0.046 \\
\hline 2 & Tangzhen Commodity Housing & $250 \times 250$ & 3 & $765 ; 720 ; 810$ & 765 & 0.083 \\
\hline 3 & Shanghai F1 Speedway & $250 \times 250$ & 3 & $980 ; 900 ; 1000$ & 960 & 0.055 \\
\hline 4 & Yueda Residential Building & $300 \times 300$ & 3 & $462 ; 594 ; 600$ & 552 & 0.141 \\
\hline 5 & Shenyuan Construction Site \#1 & $200 \times 200$ & 3 & $500 ; 450 ; 425$ & 458 & 0.083 \\
\hline 6 & Shenyuan Construction Site \#2 & $250 \times 250$ & 4 & $750 ; 780 ; 720 ; 636$ & 722 & 0.086 \\
\hline 7 & Kangtai Residential Building & $200 \times 200$ & 4 & $460 ; 440 ; 396 ; 480$ & 444 & 0.081 \\
\hline 8 & Shanghai Haide Apartment & $250 \times 250$ & 3 & $240 ; 270 ; 210$ & 240 & 0.125 \\
\hline 9 & Donglan Xincun & $250 \times 250$ & 8 & $\begin{array}{l}700 ; 770 ; 840 ; 770 ; \\
700 ; 770 ; 840 ; 630\end{array}$ & 753 & 0.096 \\
\hline 10 & Xincheng Residential Building & $250 \times 250$ & 5 & $\begin{array}{l}540 ; 540 ; 600 ; 540 ; \\
540\end{array}$ & 552 & 0.049 \\
\hline 11 & Rongnanyuan Extension & $250 \times 250$ & 11 & $\begin{array}{l}\text { 403; 403; 403; 403; } \\
\text { 403; 403; 403; 403; } \\
403 ; 403 ; 358\end{array}$ & 399 & 0.034 \\
\hline 12 & Qingchi Project Phase I & $250 \times 250$ & 3 & $567 ; 491 ; 567$ & 542 & 0.081 \\
\hline 13 & Shanghai Dekui Plant & $250 \times 250$ & 8 & $\begin{array}{l}461 ; 461 ; 461 ; 461 ; \\
461 ; 461 ; 461 ; 403\end{array}$ & 454 & 0.045 \\
\hline 14 & 2205 Gonghexin Rd & $250 \times 250$ & 3 & $736 ; 736 ; 644$ & 705 & 0.075 \\
\hline 15 & Shanghai Tennis Club & $300 \times 300$ & 3 & $720 ; 600 ; 720$ & & 0.102 \\
\hline 16 & Jinda Residential Building & $300 \times 300$ & 14 & $\begin{array}{l}786 ; 672 ; 784 ; 896 \\
672 ; 896 ; 672 ; 784 ; \\
784 ; 784 ; 1008 ; \\
1008 ; 1008 ; 1008\end{array}$ & 840 & 0.155 \\
\hline 17 & Runjiang Project Phase I & $300 \times 300$ & 3 & $448 ; 538 ; 538$ & 508 & 0.102 \\
\hline 18 & Wenhuayuan Phase V & $350 \times 350$ & 3 & $1550 ; 1639 ; 1806$ & 1665 & 0.078 \\
\hline 19 & Shanghai Dingxin Apartment & $350 \times 350$ & 8 & $\begin{array}{l}1280 ; 1440 ; 1280 \\
1280 ; 1280 ; 1280 \\
1600 ; 1600\end{array}$ & 1380 & 0.106 \\
\hline 20 & ECNU Middle School & $350 \times 350$ & 3 & $630 ; 720 ; 717$ & 689 & 0.074 \\
\hline 21 & ECNU Science Park & $350 \times 350$ & 6 & $\begin{array}{l}\text { 1079; } 960 ; 960 ; 960 ; \\
969 ; 969\end{array}$ & 983 & 0.048 \\
\hline 22 & Feilipu Plant & $400 \times 400$ & 3 & $1425 ; 1425 ; 1350$ & 1440 & 0.031 \\
\hline 23 & Site \#2 & - & 3 & $1250 ; 1200 ; 1500$ & 1317 & 0.122 \\
\hline 24 & Site \#4 & - & 3 & $2700 ; 2300 ; 2600$ & 2533 & 0.082 \\
\hline
\end{tabular}


$25 \quad$ Site \#7

26 Site \#9

27 Site \#14

28 Site \#19

29 Site \#24

30 Site \#30

31 Site \#31

32 Site \#32

\begin{tabular}{lllll}
- & 4 & $470 ; 560 ; 440 ; 420$ & 473 & 0.131 \\
- & 3 & $890 ; 1050 ; 1100$ & 1013 & 0.108 \\
- & 3 & $1300 ; 1520 ; 1550$ & 1457 & 0.094 \\
- & 4 & - & - & 0.060 \\
- & 3 & - & - & 0.080 \\
- & 4 & - & - & 0.103 \\
- & 4 & - & - & 0.122 \\
- & 4 & - & - & 0.097 \\
\hline
\end{tabular}


Table 2. Summary of bored piles for code calibration (modified after Li et al. 2015)

\begin{tabular}{|c|c|c|c|c|c|c|c|}
\hline \multirow[t]{2}{*}{$\begin{array}{l}\text { Site } \\
\text { No. }\end{array}$} & \multirow[t]{2}{*}{ Site Name } & \multirow[t]{2}{*}{$\begin{array}{l}\text { Diamete } \\
(\mathrm{mm})\end{array}$} & \multirow[t]{2}{*}{$\begin{array}{l}\text { r No. of } \\
\text { piles }\end{array}$} & \multirow[t]{2}{*}{$\begin{array}{l}\text { Measured ultimate } \\
\text { bearing capacity }(\mathrm{kN})\end{array}$} & \multicolumn{2}{|c|}{$\begin{array}{l}\text { Statistics of } \\
\text { measured bearing } \\
\text { capacity }\end{array}$} & \multirow{2}{*}{$\begin{array}{l}\text { Predicted } \\
\text { bearing capacity } \\
\text { using DT } \\
\text { method }(\mathrm{kN})\end{array}$} \\
\hline & & & & & Mean $(\mathrm{kN})$ & $\mathrm{COV}$ & \\
\hline 1 & Zhongjian Mansion & 850 & 3 & $8192 ; 8192 ; 7168$ & 7850 & 0.075 & 9717 \\
\hline 2 & Metro Line 10 Parking Lot 1 & 600 & 3 & $4008 ; 5025 ; 3685$ & 4239 & 0.131 & 3900 \\
\hline 3 & Metro Line 10 Parking Lot 2 & 600 & 4 & $3900 ; 3600 ; 3600 ; 3300$ & 3600 & 0.068 & 2965 \\
\hline 4 & Yuyuan Community & 550 & 6 & $\begin{array}{l}2420 ; 2420 ; 2240 ; 1960 ; \\
2240 ; 2800\end{array}$ & 2347 & 0.119 & 2140 \\
\hline 5 & Gaofufang & 700 & 3 & $8840 ; 8840 ; 7480$ & 8387 & 0.094 & 7572 \\
\hline 6 & Shanghai Quality Inspection & 650 & 3 & $1860 ; 1780 ; 1670$ & 1770 & 0.054 & 2218 \\
\hline 7 & Taihongxinyuan & 600 & 5 & $\begin{array}{l}2700 ; 2700 ; 3000 ; 2700 ; \\
2700\end{array}$ & 2760 & 0.049 & 2830 \\
\hline 8 & Yueyang Plaza & 850 & 3 & $10000 ; 8000 ; 11500$ & 9833 & 0.179 & 11,529 \\
\hline 9 & $\begin{array}{l}\text { Zhongsheng Commercial } \\
\text { Center }\end{array}$ & 900 & 3 & $5460 ; 5460 ; 4550$ & 5157 & 0.102 & 4078 \\
\hline 10 & Chunguang Garment Factory & 600 & 4 & $2400 ; 2400 ; 2400 ; 2700$ & 2475 & 0.061 & 3273 \\
\hline
\end{tabular}


Table 3. Summary of resistance bias factor statistics used in calibration and resulting calibrated partial factors (modified after Li et al. 2015)

\begin{tabular}{cccccc}
\hline & & Driven piles & & \multicolumn{2}{c}{ Bored piles } \\
& LT method & DT method & CPT method & LT method & LT method \\
\hline$\lambda_{R 1}$ & 1 & 1 & 1 & 1 & 1 \\
$\mathrm{COV}_{R 1}$ & 0.087 & 0.087 & 0.087 & 0.093 & 0.093 \\
$\lambda_{R 2}$ & 1 & 1.025 & 1.006 & 1 & 0.996 \\
$\mathrm{COV}_{R 2}$ & 0 & 0.144 & 0.093 & 0 & 0.184 \\
$\lambda_{R}$ & 1 & 1.025 & 1.006 & 1 & 0.996 \\
$\mathrm{COV}_{R}$ & 0.087 & 0.168 & 0.127 & 0.093 & 0.206 \\
$\gamma_{R}$ & 1.53 & 1.93 & 1.72 & 1.56 & 2.26 \\
\hline
\end{tabular}


Table 4. Feasibility robustness of calibrated partial factors in Li et al. (2015) obtained from MCS and PEM

\begin{tabular}{cccccc}
\hline \multirow{2}{*}{ Approach } & LT method & DT method & CPT method & LT method & DT method \\
\hline MCS & 0.534 & 0.489 & 0.515 & 0.558 & 0.500 \\
PEM & 0.541 & 0.479 & 0.506 & 0.578 & 0.464 \\
\hline
\end{tabular}

* The numerical entries in this table are feasibility robustness, $P\left[\left(\beta^{-} \beta_{T}\right) \geq 0\right]$. 
Table 5. Calibrated resistance factors $\left(\gamma_{R}\right)$ for load-carrying capacity at different feasibility robustness levels

\begin{tabular}{cccccc}
\hline \multirow{2}{*}{$P_{0}$} & LT method & Driven piles & \multicolumn{2}{c}{ Bored piles } \\
& 1.52 & 1.95 & 1.72 & 1.53 & 2.30 \\
0.5 & 1.55 & 1.98 & 1.75 & 1.57 & 2.34 \\
0.6 & 1.59 & 2.01 & 1.79 & 1.62 & 2.38 \\
0.7 & 1.64 & 2.05 & 1.83 & 1.69 & 2.44 \\
0.8 & 1.72 & 2.11 & 1.90 & 1.81 & 2.52 \\
0.9 & 2.04 & 2.27 & 2.10 & 2.39 & 2.76 \\
0.99 & & & CPT method & LT method & DT method \\
\hline
\end{tabular}

* Load factors used in this calibration are: $\gamma_{L}=1.0$ and $\gamma_{D}=1.0$ (Shanghai code) 
Table 6. Values of $\mu_{\beta}$ and $\sigma_{\beta}$ at various feasibility robustness levels

\begin{tabular}{ccccccccccc}
\hline \multicolumn{1}{c}{ Driven piles } & \multicolumn{4}{c}{ Bored piles } \\
$P_{0}$ & LT method & \multicolumn{1}{c}{ DT method } & \multicolumn{3}{c}{ CPT method } & \multicolumn{2}{c}{ LT method } & \multicolumn{2}{c}{ DT method } \\
& $\mu_{\beta}$ & $\sigma_{\beta}$ & $\mu \beta$ & $\sigma_{\beta}$ & $\mu_{\beta}$ & $\sigma_{\beta}$ & $\mu_{\beta}$ & $\sigma_{\beta}$ & $\mu_{\beta}$ & $\sigma_{\beta}$ \\
\hline 0.5 & 3.70 & 0.67 & 3.70 & 0.30 & 3.70 & 0.43 & 3.70 & 0.83 & 3.70 & 0.30 \\
0.6 & 3.88 & 0.70 & 3.79 & 0.30 & 3.80 & 0.44 & 3.90 & 0.89 & 3.79 & 0.31 \\
0.7 & 4.11 & 0.74 & 3.87 & 0.31 & 3.95 & 0.46 & 4.18 & 0.93 & 3.86 & 0.31 \\
0.8 & 4.38 & 0.79 & 3.98 & 0.32 & 4.10 & 0.47 & 4.54 & 1.01 & 3.98 & 0.32 \\
0.9 & 4.81 & 0.87 & 4.13 & 0.33 & 4.36 & 0.50 & 5.14 & 1.13 & 4.12 & 0.33 \\
0.99 & 6.32 & 1.13 & 4.53 & 0.36 & 5.04 & 0.56 & 7.56 & 1.65 & 4.54 & 0.36 \\
\hline
\end{tabular}


Table 7. Calibrated partial factors obtained from knee point of Pareto front

\begin{tabular}{lccccc}
\hline \multirow{2}{*}{ Piles } & Design method & \multicolumn{2}{c}{ Knee point } & \multicolumn{2}{c}{ Suggested } \\
& & $P_{0}$ & $\gamma_{R}$ & $P_{0}$ & $\gamma_{R}$ \\
\hline \multirow{3}{*}{ Driven piles } & LT method & 0.86 & 1.68 & 0.85 & 1.67 \\
& DT method & 0.84 & 2.07 & 0.85 & 2.08 \\
& CPT method & 0.85 & 1.86 & 0.85 & 1.86 \\
\hline \multirow{2}{*}{ Bored piles } & LT method & 0.88 & 1.78 & 0.85 & 1.74 \\
& DT method & 0.84 & 2.46 & 0.85 & 2.47 \\
\hline
\end{tabular}

* Partial factors for loads used in this calibration are: $\gamma_{L}=1.0$ and $\gamma_{D}=1.0$ (Shanghai code) 


\section{List of Figures}

Fig. 1. Cumulative frequency of the observed $\mathrm{COV}_{R 1}$ with fitted lognormal CDF for different types of piles

Fig. 2. Relative and cumulative frequency of $\beta$ associated with calibrated $\gamma_{R}$ for different types of piles and different design methods

Fig. 3. A bored pile design example

Fig. 4. Design results at various feasibility robustness levels

Fig. 5. Pareto front showing tradeoff between feasibility robustness $P_{0}$ and resistance factors $\gamma_{R}$ for different types of piles and different design methods 


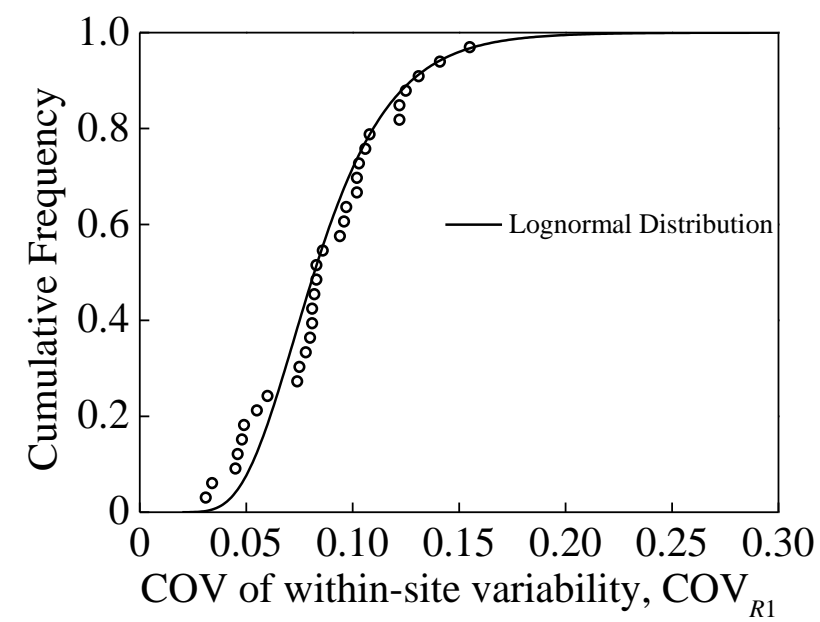

(a) Driven piles

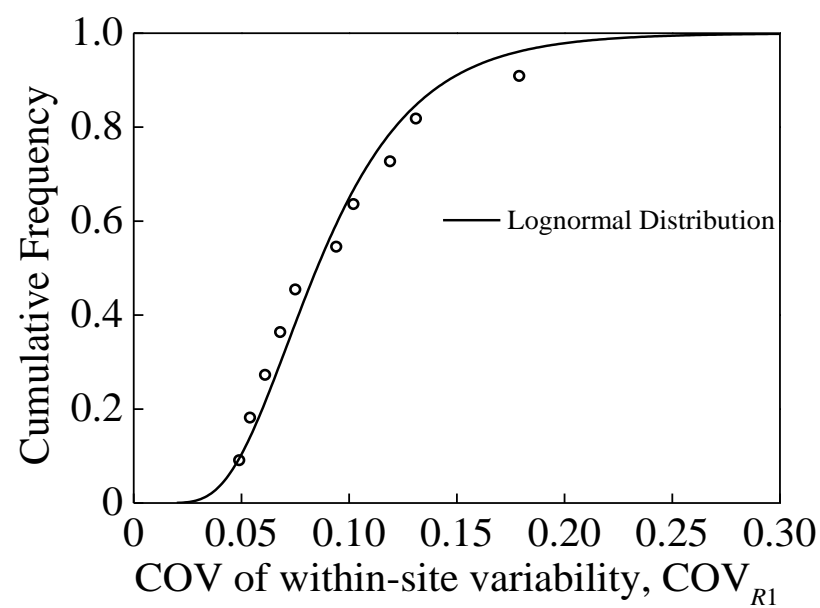

(b) Bored piles

Fig. 1. Cumulative frequency of the observed $\mathrm{COV}_{R 1}$ with fitted lognormal CDF for different types of piles 


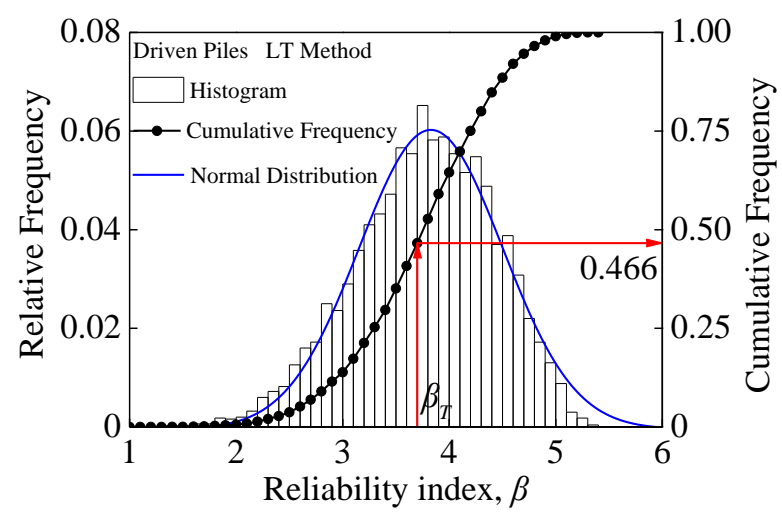

(a) Driven piles designed using LT method

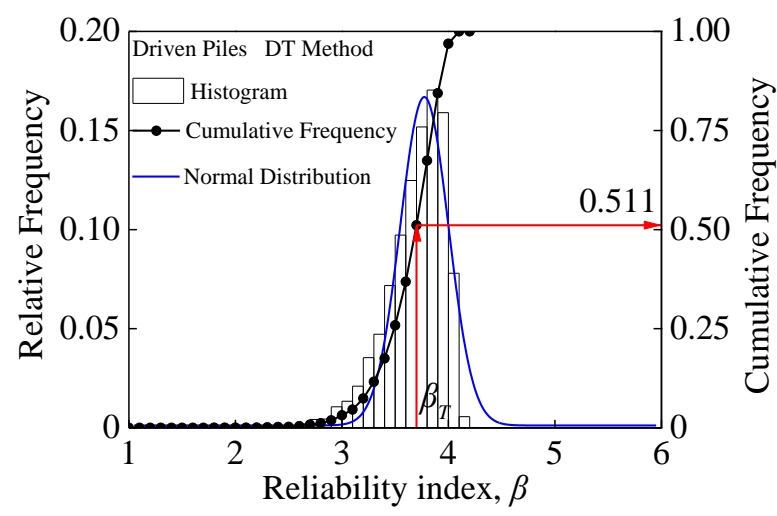

(b) Driven piles designed using DT method

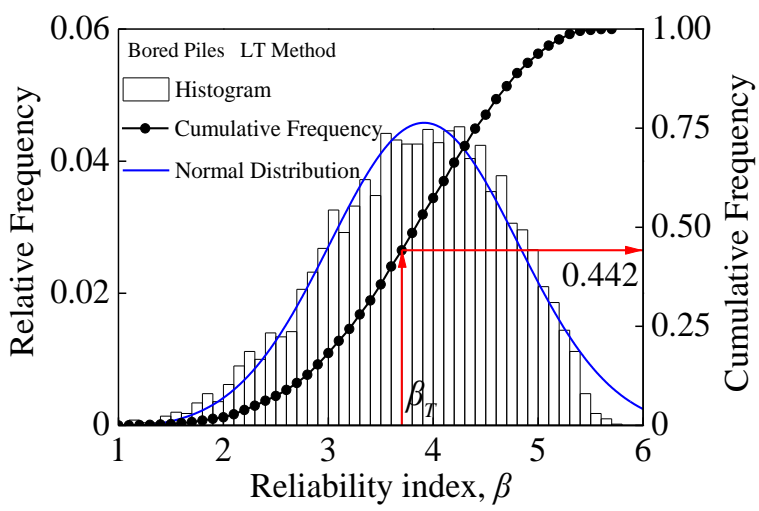

(d) Bored piles designed using LT method

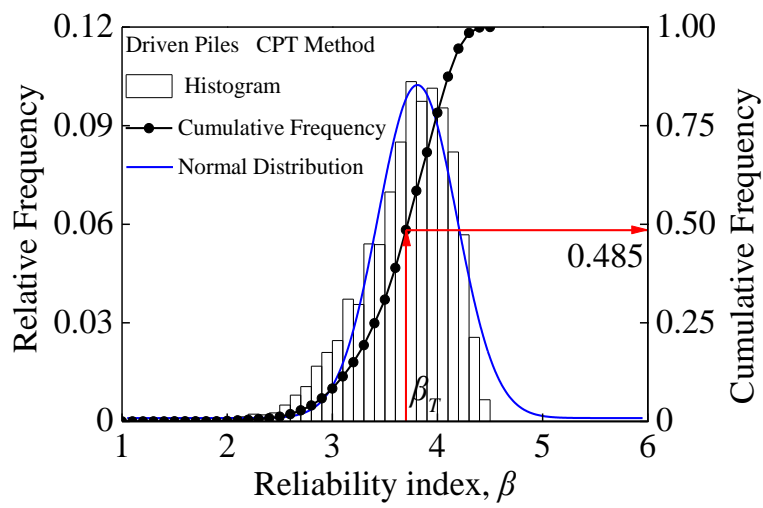

(c) Driven piles designed using CPT method

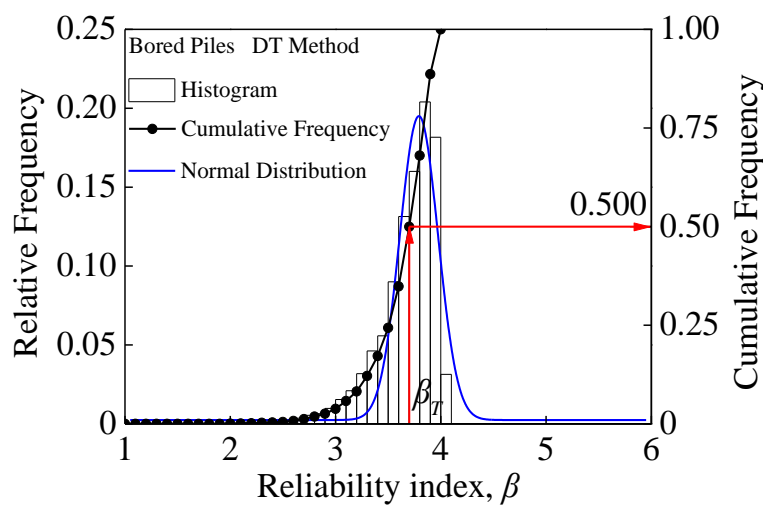

(e) Bored piles designed using DT method

Fig. 2. Relative and cumulative frequency of $\beta$ associated with calibrated $\gamma_{R}$ for different types of piles and different design methods

(Note: $\beta_{T}=3.7$ ) 


Grayish yellow clay
$f_{s}=4 \mathrm{~m}$
$d_{2}=16 \mathrm{mPa}$

Fig. 3. A bored pile design example 


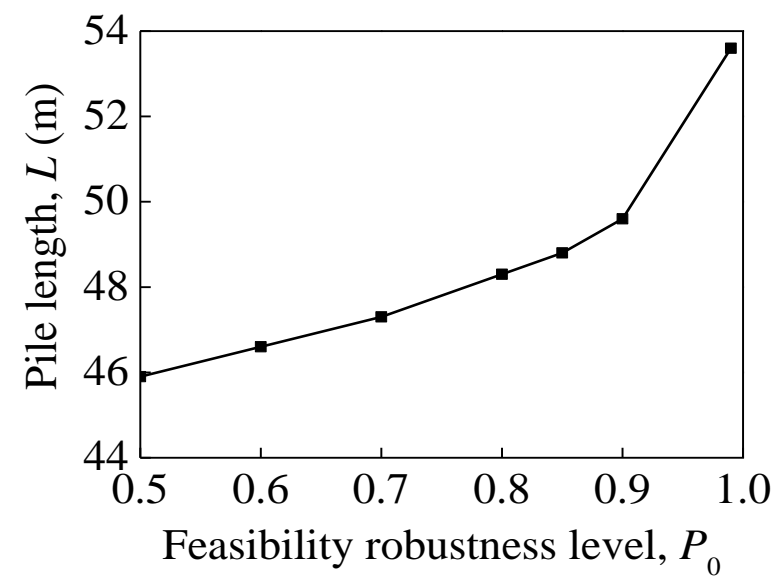

Fig. 4. Design results at various feasibility robustness levels 


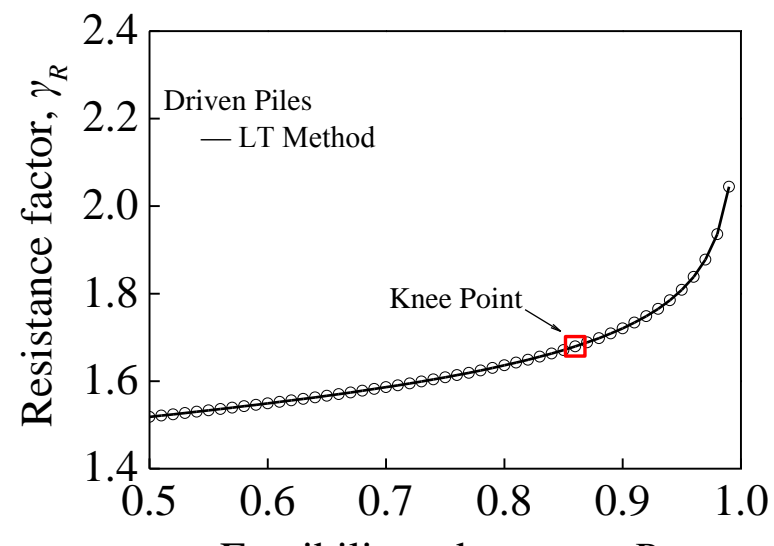

Feasibility robustness, $P_{0}$

(a) Driven piles designed using LT method

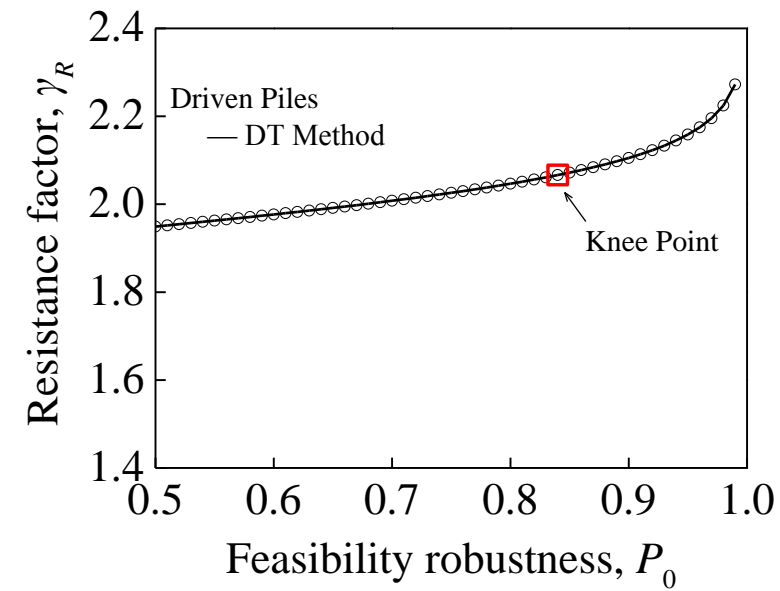

(b) Driven piles designed using DT method

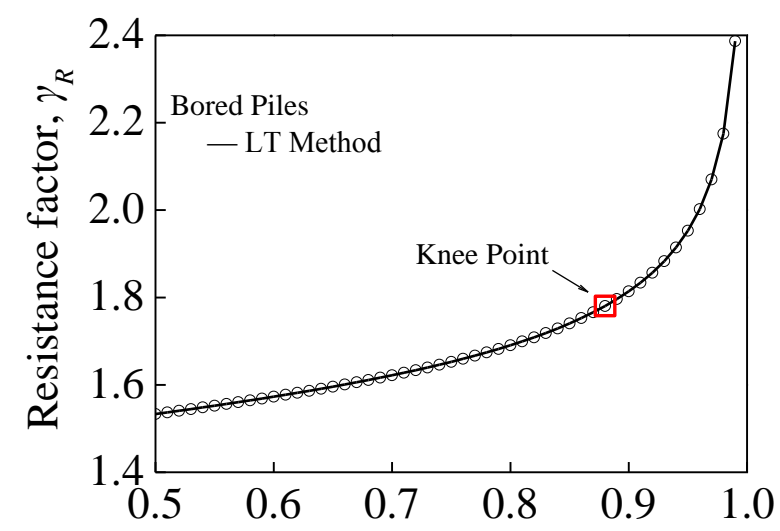

Feasibility robustness level, $P_{0}$

(d) Bored piles designed using LT method

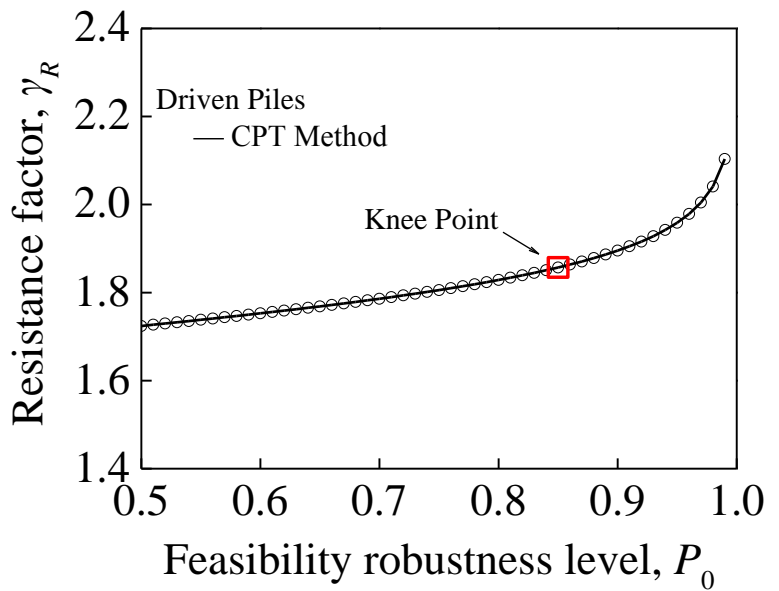

(c) Driven piles designed using CPT method

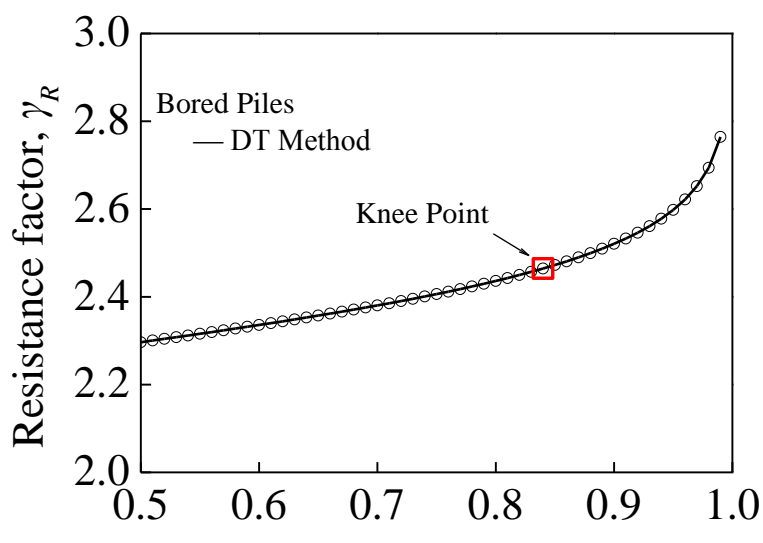

Feasibility robustness level, $P_{0}$

(e) Bored piles designed using DT method

Fig. 5. Pareto front showing tradeoff between feasibility robustness and resistance factors for different types of piles and different design methods 